\title{
Task-oriented and Purposeful Robot-Assisted Therapy
}

\author{
Michelle J Johnson, PhD 1,2,3, Kimberly J Wisneski, MS33, John Anderson 1,3, \\ Dominic Nathan 2,3, Elaine Strachota ${ }^{4}$, OTR, PhD, Judith Kosasih, MD1,3, \\ Jayne Johnston, OTR, $\mathrm{RN}^{3}$, Roger O. Smith, OTR, $\mathrm{PhD}^{5}$ \\ Medical College of Wisconsin ${ }^{1}$, Marquette University ${ }^{2}$, Clement Zablocki VA ${ }^{3}$, Concordia \\ University ${ }^{4}$, University of Wisconsin, Milwaukee ${ }^{5}$ \\ Milwaukee, Wisconsin, USA
}

\section{Introduction}

Robot-assisted therapy devices are available for rehabilitation of persons after stroke, which is the leading cause of disability among adults in the United States (AHA 2006, Volpe et al. 2002). Improving upper extremity function after stroke is critical for performance of one's life-role and the completion of unilateral and bilateral activities of daily living (ADLs). Carryover to real-life activities after rehabilitation training cannot be assumed (Sterr et al. 2000; Maclean et al. 2000; Ma and Trombly 2002; Trombly and Ma 2002; Prange et al. 2006). For example, the existence of learned non-use behavior indicates that motor gains after rehabilitation therapies may not transfer to long-term functioning on ADLs (Taub et al. 1994; Taub et al. 1999; Sterr et al. 2000). This behavior is present when persons with hemiparesis due to strokes demonstrate significant differences $\varepsilon$ between residual movement capabilities and spontaneous use of the impaired arm in real 0 world. There is a need to address barriers to the carryover of motor gains during training $\stackrel{\oplus}{.}$ to stroke function in real life.

This chapter reviews examples of current upper arm robot-assisted therapy environments $\underset{\mathrm{C}}{\mathrm{O}}$ and present findings from case study experiments with a new task-oriented, robot d therapy system focused on improving carryover of motor improvements to functional activities of daily living. We draw attention to influence of function on arm movements during robot training and explore how future environments can be more functional and engaging.

of Robot-assisted therapy devices are now being used more frequently in the rehabilitation of OO persons with physical disabilities due to neurological trauma caused by stroke and spinal $\widetilde{\pi}$ cord injury. These therapy robots provide semi- or fully-autonomous training and permit is patients using them to engage in repeated and intense practice of goal-directed tasks (Volpe \& et al 2002; Prange et al 2006; Burgar et al. 2000; Loureiro et al. 2003; Patton et al. 2006; Krebs ¿ et al. 2003; MacClellan et al. 2005, Kahn et al. 2006). Typically, the automation of therapeutic exercises involves generating trajectories that guide reaching movements and the Ф application of forces directly or indirectly to the impaired arm to assist, resist, and/or Oे passively support it during the reaching exercise. For example, the MIT-MANUS (Krebs et 
al. 2003; MacClellan et al. 2005) therapy robot permits stroke survivors to practice twodimensional (2-D) point-to-point (PTP) movements while systems like the Gentle/s (Loureiro et al. 2003) and MIME (Burgar et al. 2000) robots are capable of three dimensional (3-D) PTP training. Studies have shown that these early robotic therapy systems improve motor function as quantified by motor performance measures such as movement time and smoothness during reaching (Rohrer et al. 2002) and standard clinical measures of motor impairment such as the Upper Extremity Fugl-Meyer (UE-FM (Fugl-Meyer et al. 1975). Despite this, they have mixed impact on learned non-use and the ability to use the impaired arm in real tasks (Prange et al 2006). Given the promise of robot-assisted therapies, it is important to further investigate the mapping between practice and real-world ADL function and determine what mechanisms influence it.

Recent evidence from neuroscience literature suggests that enriched environments (Will et al 2004; Fisher and Sullivan 2001; Nudo et al. 2003), highly functional and taskoriented practice environment (Carr et al. 1985;Ada et al. 1995; Trombly et al. 1995; Aycock et al. 2004, Bayona et al. 2005; Wu et al. 2000; Woldag et al. 2003; Theilman et al. 2004), and highly motivating fun and game-based environments that increase task engagement (Bach-y-rita et al 2002, Wood et al. 2003) are important for motor relearning, recovery after stroke and reduced learned non-use behavior. Task-oriented therapies facilitate the practice of a variety of simple and complex functional movements within a real context, with environment feedback to cue task success or failure. Occupational therapists $\mathrm{Wu}$ and colleagues have shown that the presence of real objects as the target of reach significantly influences the reaching kinematics of both neurologically normal and stroke impaired persons (Wu et al. 2000, 1998). In fact, reaching towards a real object is more likely to result in smoother movements, lower movement times, and higher peak velocities. These results were also verified by Wisneski and Johnson (Wisneski and Johnson 2006, 2007) for complex ADLs such as drinking and eating. Successful examples of novel task-oriented therapy are forced-use and Constrained-Induced Movement Therapy (CIMT) (Taub et al. 1994; Taub et al. 1999; Sterr et al. 2000; Liepert et al. 2002; Page et al. 2004; Aycock et al. 2004). The training is intense and repetitive, requiring the use of the impaired arm. Data indicate that CIMT therapies reduce learned non-use, increase ADL function, and often increase the size and change the location of the cortical area representative of a muscle function (Liepert et al. 2002). These forced-use therapies often induce changes in the motor areas especially in the motor cortex and the cerebellum.

A natural question is whether combining robot-assisted therapies with a task-oriented approach involving the practice of real ADLs would improve real world functional outcomes and whether current trajectory planning processes support functional retraining on complex ADLs such as drinking and eating. The trend in the field has been towards the development task-oriented, biofeedback mechanical systems with virtual environments that permit the practice of real ADL tasks and some form of biofeedback (Huang et al. 2006). Examples of such environments include Jiping He and colleagues's RUPERT upper arm exoskeleton (He et al. 2005) and Riener and colleagues's ARMIn upper arm exoskeleton (Nef et al. 2006) that embed robot assisted training into patient-centered, engaging, and focused on daily living activities with virtual functional objects.

Currently few clinical trials exist that test whether robot-assisted therapies can be more effective when combined with a highly task-oriented therapy paradigm that focuses on the practice of ADLs in virtual or real environments. One study did examine the effect of 
adding grasping to the planar manipulation environment of the MIT-MANUS (Fasoli et al 2005). No additive effect for the reach-to-grasp practice was found but this was most likely due to differences in the intensity of training administered to the two groups and the use of motor impairment measures (the UE-FM was used to judge motor gains) to evaluate between group differences. It is still not clear what gains were made in ADL functioning on real-world tasks or how robot-assisted practice may have influenced the CNS cortical changes.

The rehabilitation robotics lab at the Medical College of Wisconsin and Marquette University has developed the Activities of Daily Living Exercise Robot (ADLER) stroke training environment, which was inspired by the Gentle/s system set-up to accommodate reaching and grasping activities in the three-dimensions (Johnson et al. 2006). Here robotassisted training is focused on improving carryover of motor gains to real life through ADL task practice and the trajectory models used to implement movement plans in 2-D and 3-D space. The chapter presents the design and several case studies to evaluate some of the main design concepts of the robot system. The ADLER was developed to train functional ADL-like tasks with and without physical objects. It capitalizes on the existing benefits of robot-assisted therapies while supporting more natural movements to position the wrist during ADL practice. Three case studies with a few able-bodied and stroke adults were conducted to evaluate the performance of the ADLER system. Case study 1 examined issues in repeatability and stability of kinematic measures such as movement time and smoothness. Case study 2 examined issues in modeling and trajectory planning of wrist movements for a real ADL task, the drink task. Case study 3 examined ADLER system's ability to reduce motor impairment and improve ADL function during the practice of point-to-point (PTP) movements that mimic real ADL tasks. Overall, these case studies show that the system has the potential to be effective in training of the upper arm after stroke with future work focused on the ability to improve both reaching and grasping abilities in the long-term.

\section{Activities of Daily Living Exercise Robot (ADLER)}

\subsection{Hardware}

ADLER is a robot therapy environment developed to permit training of real-life functional tasks involving reach, grasp, and object transportation in both 2-D and 3-D space (Fig. 1ab) (Johnson et al. 2006). The system is designed to support seated functional tasks such as grooming, drinking, eating, and desktop vocational tasks such as game playing tasks including tic-tac-toe. ADLER uses a HapticMaster robot (FCS Robotics) to assist an impaired arm along trajectories for real-life tasks and administer customized forces along programmed trajectories. The HapticMaster is an admittancecontrolled, 6 degrees of freedom (DOFs) robot. Three active DOFs position the hand in space. The end-effector of the robot can pivot 1 full radian and has a vertical range of $0.40 \mathrm{~m}$. The arm pivots about a post, with end-effector positions ranging between a radius of $0.28 \mathrm{~m}$ and $0.64 \mathrm{~m}$. A three-axis force sensor located at the end-effector measures interaction forces ( 3 DOF) generated during the tasks. The three remaining DOFs orient the wrist passively through rotation of a three-axis gimbal. Fig. $1 \mathrm{~b}$ illustrates the range of gimbal position in the ADLER environment with an approximation of the actual task space, which is often extended beyond the endeffector, depending on the orthosis used. 
Several custom-designed orthoses have been designed for attaching an impaired limb to the gimbal at either the wrist or the forearm (close to the elbow) without impeding grasp. The configuration permits the subject to orient freely their hand as needed to grasp and use an object (Fig. 2ab). Orthoses have also been constructed to support lower-functioning stroke survivors that have no grasp capability, i.e. those that need to begin training in the reaching phase only (Fig. 2c).

A custom-made glove is designed to assist in functional grasping as needed (Nathan and Johnson 2007). The glove uses bend sensors (Flexpoint Sensor Systems) to detect finger joint angle changes between 0 and 90 degrees. Sensors measure the joint angles of the 2 nd interphalangeal joint (PIP) of the index finger and the distal interphalangeal joint of the thumb during the tracking movements. At present only the index finger and thumb is incorporated since these are most often involved in ADLs to complete whole arm grasp, pinch and cyinder grips (Ada et al. 1995). The glove can be used with a functional electrical stimulation (FES) unit to assist in voluntary grasp and release or passive grasp and release. The current glove design is minimally evasive and does not interfere during task performance and to allow appropriate hand shaping before and during grasp with open-ended finger tips to allow haptic feedback and better grasping and shaping of the hand.

Patients using the ADLER system are asked to sit on a rail-mounted chair that can be easily pushed into position. The chair can be positioned on either side of the table. The table height is adjustable, and a custom-made harness is available to restrain motion of the trunk. To ensure subject safety during robot therapy, three safety systems are integrated into ADLER. First, power to the robot can be cut (halting any motion of the arm) and all systems shut down with the use of an emergency stop button held by an experimenter. The second safety system, controlled by the subject, is a foot pedal placed under the dominant foot that must be depressed during any operation of the robot. If at any time the subject lifts his or her foot off the pedal, the robot halts all motion. Finally, all orthoses attach to the gimbal magnetically with a pair of solenoids. Current through the two solenoids is automatically stopped if a force overload is detected and the orthoses detaches.

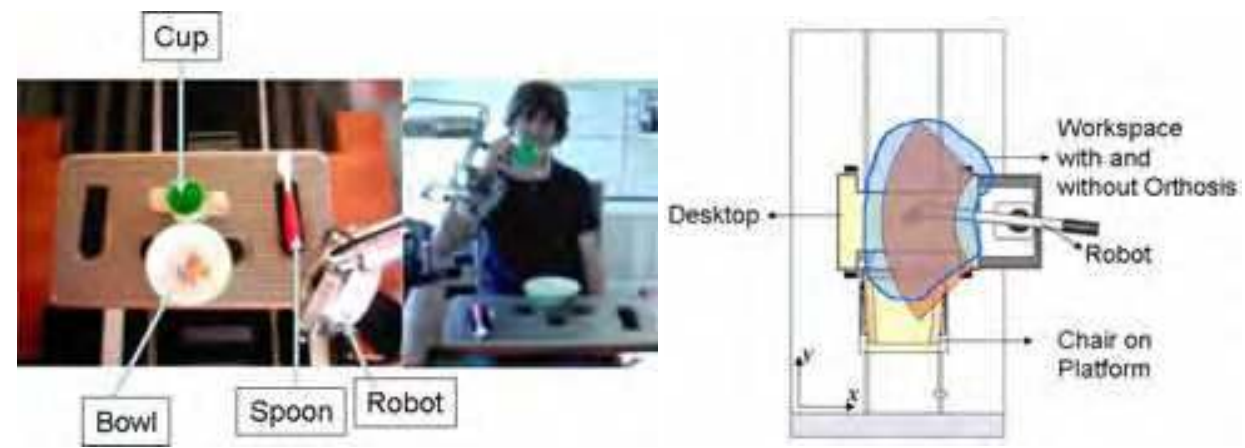

Fig. 1. The set-up for the ADLER stroke therapy system.

The system consists of an activity table and tray for selfcare-like tasks such as eating. The chair is on guide rails that permit it to be adjusted and mounted on either side of the table. The HapticMaster robot is the main system used and is customized wrist orthosis that permits the hands to be free for 3-D spatial functional movements such as drinking. 


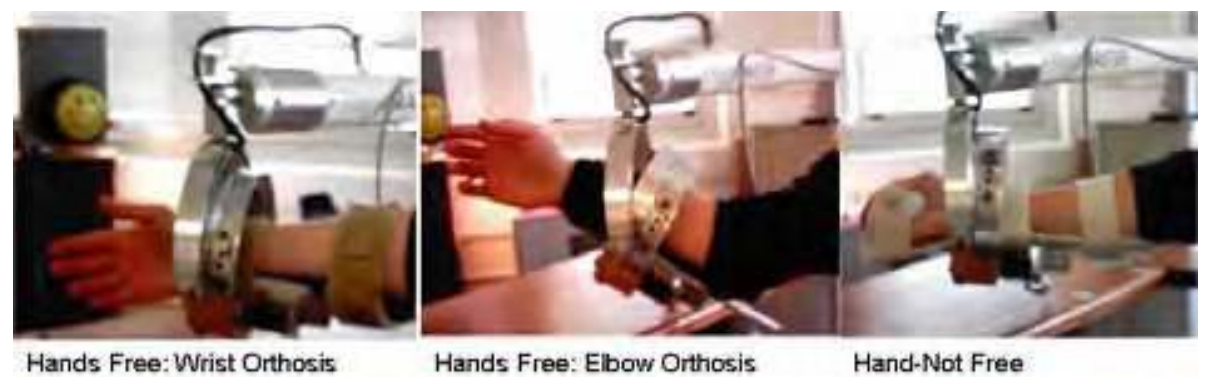

Fig. 2a-c. The ADLER Orthoses.

Three orthoses for ADLER; depending on the protocol used and tasks, these orthoses are interchangeable with the system.

\subsection{Software}

The ADLER system uses a custom-designed software called HERALD to implement various upper arm functional movements. The HERALD software, flow-charted in Fig. 3a, uses HapticAPI (FCS Robotics Manual 2003) to control the HapticMaster robot and Crystal Space v0.98 (Tyberghein et al. 2004), a freeware for creating graphical user interfaces (GUIs), to render the simulated environment. Crystal Space is an open-source engine that is platform and application programming interface (API) independent. In the ADLER system, we use this engine within a PC-based Windows XP environment. The safety signals from the foot pedal and emergency stop are also monitored by HERALD. The glove signals are also monitored so that the glove collection rate can be synchronized with the robot system.

In HERALD, the experimenter can define all the parameters for a task and the training modes. The experimenter is able to program arm movements on-the-fly using start, end, and multiple via points or upload the data from a file storing real or pre-defined trajectories. HERALD can also be used to set boundaries within the robotic workspace, for example, to prevent the gimbal from scraping against the table.
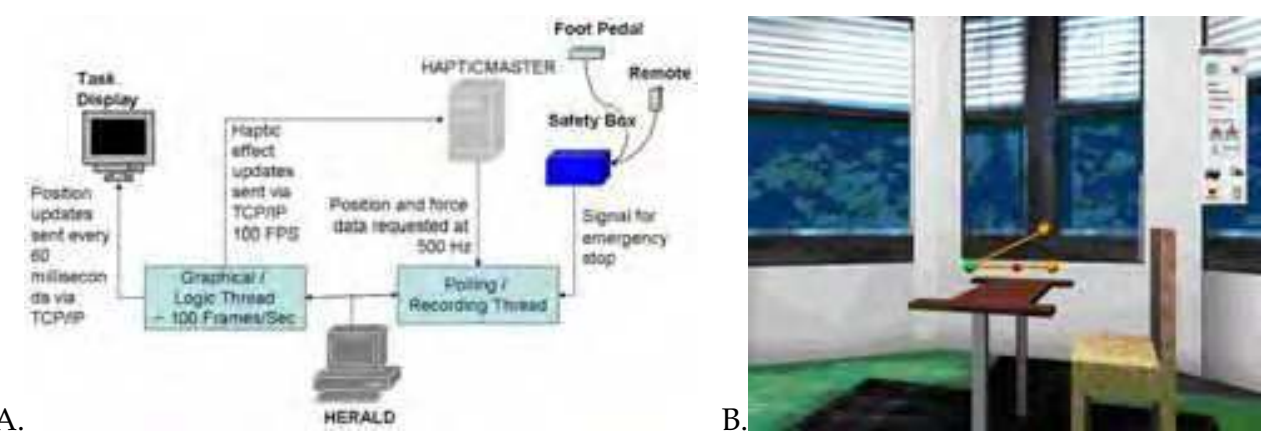

Fig. 3. HERALD Control software.

a. Signal flow to and from HERALD. b. Graphical interface where spheres denote via-points with straight line trajectories. Colored dots indicate the gimbal position and the current target via-point. 
HERALD's graphical interface displays a one-to-one mapping of the task environment, which consists of the platform, table, chair, and straight-line or curved connections to the key points in the trajectories (Fig. 3b). Typically, one of the experimenters operates the computer and monitors the therapy on-screen. Audio cues signal acquisition of key events that correspond to pre-programmed points in the real task, providing feedback to the user and experimenters. The system actively acquires the position and the orientation of the gimbal center as well as the forces on the end-effecter at up to $1250 \mathrm{~Hz}$. Training session data are stored automatically.

\subsection{Training Paradigms in ADLER}

In order to accommodate a range of training protocols, ADLER is able to operate in three modes: normal, form, and function. Normal mode permits unconstrained subject motion anywhere within the robot workspace. In form mode the subject is constrained to move along a defined path between via-points. When a via-point is reached, the robot emits an audible cue and continues along a new path to the next point. The robot pulls the user with a spring force traveling at a minimum velocity set by the experimenters. In function mode the subject is constrained to a cylindrical space around the defined path between via-points, allowing more freedom than form mode. A spring force, again with a minimum velocity, pulls the user towards and along the axial path. When the user moves into a defined spherical volume around each via-point called a pull zone, a spring force pulls the user radially towards the via-point. Form and function modes are illustrated in Fig. 4. Assistance can be provided in form and function modes by increasing the spring constant, or removed entirely by setting the spring constant to zero. The robot can also resist user motion in any mode by setting a velocity-dependent damping coefficient.


Fig. 4. Movement Modes.

Form (a) versus function (b) concept implemented in the ADLER training modes. The subject performed in function and form modes. The subject starts at location in upper left quadrant. The functional mode allowed for more natural trajectories.

Subjects using ADLER may be classified as high, medium, or low functioning. ADL training protocols have been developed for each. High functioning subjects train with tasks that involve grasping and manipulating objects. Medium and low-functioning subjects may begin by performing PTP tasks that mimic functional ADLs and then progress to 
performing reaching and grasping tasks with the FES Grasp glove integrated with ADLER. Table 1 displays some of the training tasks currently programmed in ADLER. Subjects are evaluated in the normal mode with the tasks from Table 1 or additional evaluation tasks as shown in Table 2.

\subsubsection{Point-to-Point Reaching Robot Training}

Two-dimensional reaching movements are guided by a flat-screen computer monitor on the activity table (Fig. 5a). Subjects move from one highlighted point to another, tracing predefined shapes and paths. While the entire monitor is contained within the robotic workspace, certain points can be excluded if the subject is not able to reach them. Three dimensional reaching movements are designed to be similar to those of functional activities. For instance, to mimic the actions of drinking from a cup, the subject may be asked to touch a point on the activity table, reach up to his/her mouth, touch the table again, and return his/her hand to rest. Subjects can practice these tasks repeatedly and at different levels of assistance or resistance.

\subsubsection{Task-oriented Robot Training}

Task-oriented robot training consists of functional, self-care tasks such as eating, drinking (Fig. 5 and Tables 1 and 2), combing hair, game-playing tasks such as tic-tac-toe (against the experiment or against the computer, and household manipulation tasks such as ringing a bell or opening doors and locks. Typically, game-playing tasks are only performed in normal mode, but robot impedance characteristics can be modified to react faster or slower in response to the forces on the end-effector. Task-oriented robot-assistance can be performed in any of the three modes.

\begin{tabular}{|l|l|l|l|}
\hline & $\begin{array}{l}\text { Task } \\
\text { Name }\end{array}$ & High-ADL & Low-ADL \\
\hline ADLs & Drink & $\begin{array}{l}\text { Subject reaches, grasps and lifts a } \\
\text { cup; drinks; returns cup. }\end{array}$ & $\begin{array}{l}\text { Subject reaches, touches } \\
\text { red dot; touches mouth; } \\
\text { touches red dot. }\end{array}$ \\
\cline { 2 - 5 } & Comb & $\begin{array}{l}\text { Subject reaches, grasps, and lifts a } \\
\text { comb; lifts comb to side of head; combs } \\
\text { up and down twice; returns comb. }\end{array}$ & $\begin{array}{l}\text { Subject reaches, touches } \\
\text { blue dot; touches side of } \\
\text { head; touches blue dot. }\end{array}$ \\
\hline PTP & Reaching & $\begin{array}{l}\text { Subject reaches straight out, presses a } \\
\text { buzzer }\end{array}$ & $\begin{array}{l}\text { Subject reaches straight out } \\
\text { to a colored dot }\end{array}$ \\
\cline { 2 - 5 } & $\begin{array}{l}\text { Point-to- } \\
\text { point }\end{array}$ & $\begin{array}{l}\text { Subject traces a 2-D pattern with a } \\
\text { pointer. }\end{array}$ & $\begin{array}{l}\text { Subject follows a 2-D } \\
\text { pattern without a pointer. }\end{array}$ \\
\hline tasks & Doors & $\begin{array}{l}\text { Subject performs a sequence of tasks } \\
\text { that unlocks and opens nine different } \\
\text { doors. }\end{array}$ & $\begin{array}{l}\text { Subject reaches and touches } \\
\text { nine sets of colored dots in } \\
\text { specific sequences. }\end{array}$ \\
\hline Fun & $\begin{array}{l}\text { Tic-tac- } \\
\text { toe }\end{array}$ & $\begin{array}{l}\text { Subject plays tic-tac-toe in normal } \\
\text { mode with custom-designed board } \\
\text { and pieces }\end{array}$ & N/A \\
\cline { 2 - 5 } & Plinko & $\begin{array}{l}\text { Subject plays drops a ping pong ball } \\
\text { into plinko game in normal mode }\end{array}$ & N/A \\
\hline
\end{tabular}

Table 1. Examples of training tasks on ADLER. 
ADLER supports several categories of task from selfcare tasks such as feeding and drinking, reaching tasks in $2 \mathrm{D}$ and $3 \mathrm{D}$ space and fun tasks.

\begin{tabular}{|l|l|}
\hline Task Name & \multicolumn{1}{c|}{ Description } \\
\hline Reach & Subject reaches outward to six points \\
\hline Drink & $\begin{array}{l}\text { Subject reaches, grasps and lifts a cup with one hand; } \\
\text { drinks; returns cup. }\end{array}$ \\
\hline Bilateral Drink & $\begin{array}{l}\text { Subject reaches, grasps and lifts a cup with both hands; } \\
\text { drinks; returns cup. }\end{array}$ \\
\hline Point-to-Point & Subject traces circle and cross patterns \\
\hline Jebsen-Taylor & Subject performs a Jebsen-Taylor evaluation task \\
\hline
\end{tabular}

Table 2. Evaluation tasks supported on ADLER.

ADLER supports several evaluation tasks that are performed without forces in the normal mode. From selfcare tasks such as feeding and drinking, reaching tasks in 2D and 3D space and fun tasks.



Fig. 5. ADLER Activities.

The ADL activity table set up in the ADLER environment; a. 2-D PTP reaching; b. patient practicing functional reaching; $\mathrm{c}$. patient practicing manipulation.

\subsection{Trajectory Planning for Functional and More Natural Wrist Movements}

Typically, robot-mediated movements between via-points in reaching tasks are modeled on the minimum jerk theory of movement (Flash \& Hogan, 1985; Flash \& Hogan, 1987; Amirabdollahian et al. 2003; Loureiro et al. 2003). The minimum jerk algorithm defines straight-line movements and bell shaped velocity curves with zero starting and ending velocities. However, more complex models may be necessary to describe reaching during ADLs. The presence of a real object modifies the orientation of the wrist for the reach-tograsp movement (Gentilucci et al. 1991, 1996, 2002; Gentilucci, 2005; Wu et al. 1998; Wu et al. 2000). Loureiro and colleagues, in their study of 3-D tracking in the Gentle/s robot-assisted therapy environment, proposed the use of 7 th order polynomial curves with varying boundary conditions to better approximate reaching towards real objects (Loureiro et al. 2003; Amirabdollahian et al. 2003).

We had investigated the influence of objects on reaching movements and compared the results to a popular current trajectory model called the minimum-jerk model (Wisneski \& 
Johnson 2007). Wrist movements were significantly curved away from a predicted straight line and they were curved to accommodate task constraints such as the table, a cup handle, or an obstacle. Supporting real task trajectories means identifying trajectory planning models that better account for curvatures observed in real tasks. We have also developed a 5 th order model based on curvature equations reported by Flash and Hogan with modified input conditions (Flash \& Hogan, 1985; Flash \& Hogan, 1987). The models are described in Fig. 6 and show the contrast in how accurately the models approximate the actual trajectories. Wisneski \& Johnson demonstrated that the model with curvature consideration is adequate for functional task planning (providing the input conditions in Table 4 are well defined) however the basic minimum-jerk model without curvature is adequate for PTP movement and planar movements (Wisneski \& Johnson 2007). Table 3 shows the relevant equations for these raw data along with the raw subject data. The minimum jerk model with curvature considerations combined with the model inputs for via points was a better fit than the basic model (Model A in Table 3). The model inputs lead to significant reduction of area between data curves; these area reductions were seen for all events as compared to the original minimum jerk paradigm (Model $\mathrm{C}-5^{\text {th }}$ order with initial conditions such as those seen in Table 4 for the drink task).


Fig. 6. Trajectory Planning Fits.

Three trajectory models supported by ADLER and an actual trajectory defined from motion analysis studies for a reach to a cup during drinking. Model $C$ based on the $5^{\text {th }}$ order trajectory with curvature and end-point considerations was the best fit for $\mathrm{X}-\mathrm{Y}$ and $\mathrm{X}-\mathrm{Z}$ planes.

\section{Case Studies}

\subsection{Methods}

Three case studies presented below examine how two healthy, right-handed normalfunctioning adults and a low-functioning stroke survivor used and experienced ADLER and its various modes. All subjects gave informed consent for the study, which was approved by the Institutional Review Board of the Clement J. Zablocki VA Medical Center. Table 5 summarizes the able-bodied subjects in this case study.

Case study 1 examines issues in repeatability and stability of kinematic measures such as movement time and smoothness. Able-bodied subjects (age 59 - S1 and age 55-S2) experienced the ADLER robot three times at the beginning and end of one week. The tasks 
for this study were defined using the $5^{\text {th }}$ order minimum jerk model (Model A, Tables 3 ). The subjects completed both reaching and grasping phases of a battery of ADLs. Only the drink task is shown and analyzed for kinematic parameters.

\begin{tabular}{|c|c|c|}
\hline Model & Defining equations and boundary conditions & \\
\hline \multirow{2}{*}{$\begin{array}{l}\text { A. } 5^{\text {th }} \\
\text { order } \\
\text { minimum } \\
\text { jerk }\end{array}$} & $\begin{array}{l}x(t)=x_{o}+\left(x_{o}-x_{f}\right)\left(15 \tau^{4}-6 \tau^{5}-10 \tau^{3}\right) \\
y(t)=y_{o}+\left(y_{o}-y_{f}\right)\left(15 \tau^{4}-6 \tau^{5}-10 \tau^{3}\right) \\
z(t)=z_{o}+\left(z_{o}-z_{f}\right)\left(15 \tau^{4}-6 \tau^{5}-10 \tau^{3}\right)\end{array}$ & \multirow{2}{*}{$\begin{array}{l}\text { The } 5^{\text {th }} \text { order minimum } \\
\text { jerk model for reaching is } \\
\text { widely used in robotic } \\
\text { therapy (Flash \& Hogan, } \\
\text { 1985; Flash \& Hogan, } \\
\text { 1987). }\end{array}$} \\
\hline & $\begin{array}{l}\text { Zero velocity, acceleration at initial and final } \\
\text { points }\end{array}$ & \\
\hline \multirow[t]{2}{*}{$\begin{array}{l}\text { B. } \\
\text { Modified } \\
7^{\text {th }} \text { order } \\
\text { minimum } \\
\quad \text { jerk }\end{array}$} & $\begin{array}{l}p(\tau)=a+b \tau+d \tau^{3}+f \tau^{5}+h \tau^{7} \text { where } \\
a=\frac{1}{2} \sum p ; b=v_{\text {mid }} ; d=-3 v_{\text {mid }}+\frac{35}{16} \Delta p \\
f=3 v_{\text {mid }}-\frac{21}{8} \Delta p ; h=-v_{\text {mid }}+\frac{15}{16} \Delta p \\
\sum p=p_{f}+p_{s} ; \Delta p=p_{f}-p_{s}\end{array}$ & \multirow[t]{2}{*}{$\begin{array}{l}\text { This modified } 7^{\text {th }} \text { order } \\
\text { model was developed by } \\
\text { Loureiro and colleagues as } \\
\text { a better approximation of } \\
\text { actual reach towards an } \\
\text { object (Loureiro et al. 2003; } \\
\text { Amirabdollahian et al. } \\
\text { 2003). }\end{array}$} \\
\hline & $\begin{array}{l}\text { Zero velocity, acceleration at initial and final } \\
\text { points. Maximum velocity and zero acceleration } \\
\text { at } 50 \% \text { reach. }\end{array}$ & \\
\hline \multirow[t]{2}{*}{$\begin{array}{l}\text { C. } 5^{\text {th }} \\
\text { order } \\
\text { curvature } \\
\text { model }\end{array}$} & $\begin{array}{l}x^{-}(\tau)=\frac{t_{f}^{5}}{720}\left(\pi_{1}\left(\tau_{1}^{4}\left(15 \tau^{4}-30 \tau^{3}\right)+\tau_{1}^{3}\left(80 \tau^{3}-30 \tau^{4}\right.\right.\right. \\
\left.\quad-60 \tau^{3} \tau_{1}^{2}+30 \tau^{4} \tau_{1}-6 \tau^{5}\right)+c_{1}\left(15 \tau^{4}-10 \tau^{3}-6\right. \\
\begin{aligned} x^{+}(\tau)=x^{-}(\tau)+\pi_{1} \frac{t_{f}^{5}\left(\tau-\tau_{1}\right)^{5}}{120} \text { where } \\
c_{1}=\frac{1}{t_{f}^{5} \tau_{1}^{2}\left(1-\tau_{1}\right)^{5}}\left(\left(x_{f}-x_{0}\right)\left(300 \tau_{1}^{5}-1200 \tau_{1}^{4}+1600 \tau_{1}^{3}\right)\right. \\
\quad+\tau_{1}^{2}\left(-720 x_{f}+120 x_{1}+600 x_{0}\right)+\left(x_{0}-x_{1}\right)\left(300 \tau_{1}-2\right. \\
\pi_{1}=\frac{1}{t_{f}^{5} \tau_{1}^{5}\left(1-\tau_{1}\right)^{5}}\left(\left(x_{f}-x_{0}\right)\left(120 \tau_{1}^{5}-300 \tau_{1}^{4}+200 \tau_{1}^{3}\right)-20\left(x_{1}-\right.\right.\end{aligned}\end{array}$ & \multirow[t]{2}{*}{$\begin{array}{l}\text { This modified } 5^{\text {th }} \text { order } \\
\text { model is based on } \\
\text { equations developed by } \\
\text { Hogan and Flash to } \\
\text { describe reaching. We } \\
\text { have applied special } \\
\text { inputs to the equations } \\
\text { based on motion analysis } \\
\text { studies to approximate } \\
\text { functional reaching. }\end{array}$} \\
\hline & $\begin{array}{l}\text { Zero velocity, acceleration at initial and final } \\
\text { points. Via point }\left(\mathrm{x}_{1}, \mathrm{y}_{1}, \mathrm{z}_{1}\right) \text { defined at time } \tau_{1}=0.4 \\
(40 \% \text { of reach). }\end{array}$ & \\
\hline
\end{tabular}

Table 3. Summary of Trajectory Planning Models Investigated.

Three trajectory models supported by ADLER and an actual trajectory defined from motion analysis studies. The critical time for via points and the Cartesian inputs are as X1, Y1, and Z1. 


\begin{tabular}{|c|c|c|c|c|c|c|}
\hline $\begin{array}{c}\text { Model } \\
\text { Input\# }\end{array}$ & Purpose & $\begin{array}{c}\text { Applicable } \\
\text { Events }\end{array}$ & $\boldsymbol{t 1}$ & X1 & Y1 & Z1 \\
\hline 1 & Table Constraint & 'Reach' & .40 & N/A & N/A & $42 \mathrm{~mm}$ \\
& 'Rest' & .40 & N/A & N/A & $28 \mathrm{~mm}$ \\
\hline 2 & TC+Cup & 'Reach' & .40 & $39 \mathrm{~mm}$ & N/A & T.C. + $12 \mathrm{~mm}$ \\
& Manipulation & 'Rest' & .40 & $39 \mathrm{~mm}$ & N/A & T.C. $+7 \mathrm{~mm}$ \\
\hline 3 & Movement out-of- & 'To Mouth' & .40 & $\mathrm{~N} / \mathrm{A}$ & $\mathrm{N} / \mathrm{A}$ & $59 \mathrm{~mm}$ \\
& the-plane (MOP) & 'Return Object' & .40 & $\mathrm{~N} / \mathrm{A}$ & $\mathrm{N} / \mathrm{A}$ & $59 \mathrm{~mm}$ \\
\hline 4 & MOP + a cup-type & 'To Mouth' & .23 & $16 \mathrm{~mm}$ & $\mathrm{~N} / \mathrm{A}$ & $10.5 \mathrm{~mm}$ \\
& object & 'Return Object' & .40 & $16 \mathrm{~mm}$ & $\mathrm{~N} / \mathrm{A}$ & $10.5 \mathrm{~mm}$ \\
\hline
\end{tabular}

Table 4. Settings of Model C for A Drink Task.

Summary of input and output points used to define Model B for a drinking task using a cup with one hand. This setting is also used with Case Study 2.

Case study 2 examines issues in modeling and trajectory planning of wrist movements for a real ADL task, the drink task. An able-bodied subject (age 22 - S3) experienced the ADLER robot with two different trajectory planning models in the same day and compared the results. The tasks for case study 2 were defined using either Model A or the curved model Model C with input as shown in Tables 4. These tasks were drink and feed (with spoon). They were repeated at least three times. First, the subject completed the reaching and grasping phases of the tasks without a trajectory model, i.e., the subject completed the task in normal mode with no assistance from the robot and the ADLER is only recording movement and forces. Next, the subject repeated the tasks with Models $\mathrm{A}$ and $\mathrm{C}$ and then answered questions about their experiences. Only the drink task is shown and analyzed for kinematic parameters.

Case study 3 examines ADLER system's ability to reduce motor impairment and improve ADL function during the practice of Low ADL movements (Table 1). The stroke survivor was 48 years old and sustained an ischemic stroke four years before with hemiparesis of the left side (Fig. 7).

\begin{tabular}{c|c|c|c|c|c|c|c}
\hline Subjects & Gender & $\begin{array}{c}\text { Trained } \\
\text { with }\end{array}$ & Age & Mode & $\begin{array}{c}\text { Robot Mode } \\
\text { Assist/Resist }\end{array}$ & $\begin{array}{c}\text { Motor } \\
\text { Functional level }\end{array}$ & $\begin{array}{c}\text { Trajectory } \\
\text { Model Used }\end{array}$ \\
\hline S1 & Female & $\begin{array}{c}\text { Left } \\
\text { hand }\end{array}$ & 59 & Function & Assist & Able-Bodied & $\begin{array}{c}\text { Model A } \\
\text { (Table 3) }\end{array}$ \\
\hline S2 & Male & $\begin{array}{c}\text { Left } \\
\text { hand }\end{array}$ & 55 & Form & Assist & Able-Bodied & $\begin{array}{c}\text { Model A } \\
\text { (Table 3) }\end{array}$ \\
\hline S3 & Male & $\begin{array}{c}\text { Left } \\
\text { hand }\end{array}$ & 22 & Form & Assist & Able-Bodied & $\begin{array}{c}\text { Model A } \\
\text { Model C } \\
\text { (Table 4) }\end{array}$ \\
\hline S4 & Male & $\begin{array}{c}\text { Left } \\
\text { Impaired } \\
\text { hand }\end{array}$ & 48 & Form & Assist & $\begin{array}{c}\text { Stroke(RCVA) } \\
\text { UE-FT: Level2 } \\
\text { UE-FM: 22 }\end{array}$ & $\begin{array}{c}\text { Model A } \\
\text { (Table 3) }\end{array}$ \\
\hline
\end{tabular}

Table 5. Subjects for Case Studies 1-3.

Summary of able-bodied and stroke subjects ran on ADLER. The stroke survivor had a right CVA and motor functional level (UE-FM) of 22 of 66 and an ADL functional (UE-FT) of level 2 of 7.

The stroke subject participated in the reaching aspects of the functional tasks but was not able to participate in the grasping portion (the FES glove was not worn in this instant). The 
training was conducted in form mode using 2-D and 3-D PTP reaching tasks mimicking ADLs. These tasks were programmed using Model A. As the subject improved, the force assistance (gains on the spring forces) was gradually decreased. Training sessions were administered three times per week for six weeks, with each lasting for approximately one hour. Clinical and robotic evaluations sessions using tasks in Table 2 were completed in the first, third, and last weeks of training. Clinical evaluations included upper-extremity FuglMeyer (UE-FM) and functional test (UE-FT) evaluations administered by an occupational therapist (Fugl-Meyer et al. 1975; Wilson et al. 1994). A follow-up evaluation was conducted about one month after the final training period. The ADLER evaluations, completed in normal mode (without force assist), allow for quantification of kinematic improvement without the aid of robotic assistance.

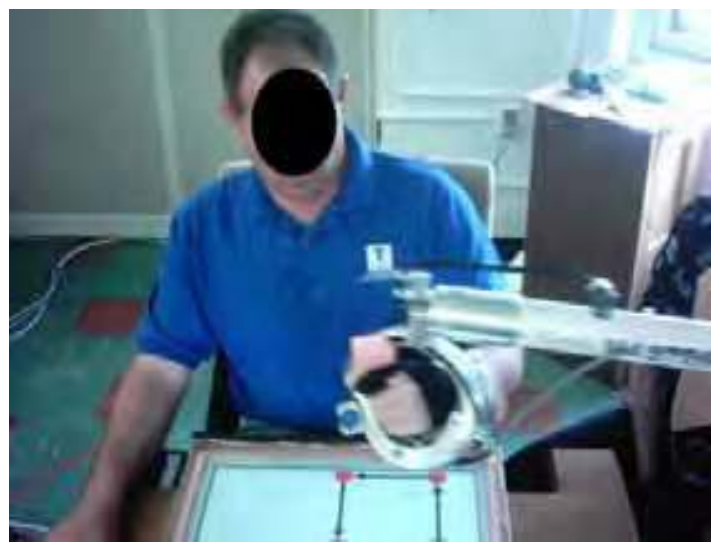

Fig. 7: Stroke Subject in ADLER.

Training takes place using ADLER to complete several low ADL tasks. The low functioning stroke is completing a 2-D PTP.

Force and position data recorded by HERALD were filtered (10 Hz Butterworth low pass) and analyzed using Matlab software (The MathWorks, Inc.). Several kinematic dependent variables were calculated for Case Studies 1 and 2. Total displacement (TD) is the total distance traveled during a given task. The total time required to complete a given task is the movement time (MT). Peak Velocity (PV) is the maximum velocity used in the task. Several measures of smoothness are calculated from the velocity profile, including the ratio of peak velocity (PV) to mean velocity. The movement smoothness (MS) is defined as the peak velocity divided by the average velocity (PV/MeanV) (Rohrer et al. 2002). Trajectories are charted on two position plots, where the initial starting position is normalized to point $(0,0,0)$. The $x-y$ plane is parallel to the activity table top, while the $\mathrm{z}$ axis points up. The responses to questions about Model A and C for case study 2 were analyzed and compared using t-test.

\subsection{Results and Discussion of Cases}

\subsubsection{Case Study 1: Repeatability and Short-term Learning}

Table 6 shows the results of the drink evaluation sessions. We expected that able-bodied subjects may have some short-term learning but that, in general, they would have minimum changes across the key kinematic variables. Subject 1 had consistent kinematics across all 
kinematic variables with low standard deviations. The fact that S2 had more variance than S1 may indicate that some subjects may require more time during training than others. In addition, we realized that a possible source of error is in the placement of artifacts during it repeatable task trial. It is important the artifacts are placed in the same location during these trials. On the other hand subject 2 only had consistent kinematics across total displacement and peak velocity. Figure 8 shows an example of the results for subject 1 .


Fig. 8. $\mathrm{XY}$ and $\mathrm{XZ}$ plane data of the drink task for subject 1 for all trials for $1^{\text {st }}$ and last evaluations.

The graphical data show all three trials and averages for days 1 and 4 . Day 1 is solid lines (thick average line) and Day 4 is dash lines (thin line average). $X Y$ is the plane of the table and $\mathrm{XZ}$ in out of the plane of the table in the plane of the person's torso.

\begin{tabular}{|c|c|c|c|c|c|c|c|c|}
\hline \multirow{3}{*}{ Subject } & \multicolumn{4}{|c|}{ Initial } & \multicolumn{4}{c|}{ Final } \\
\cline { 2 - 9 } & MT (s) & $\begin{array}{c}\text { TD } \\
(\mathbf{m})\end{array}$ & $\begin{array}{c}\text { PV } \\
(\mathbf{m} / \mathbf{s})\end{array}$ & MS & MT (s) & $\begin{array}{c}\text { TD } \\
(\mathbf{m})\end{array}$ & $\begin{array}{c}\text { PV } \\
(\mathbf{m} / \mathbf{s})\end{array}$ & MS \\
\hline \multirow{2}{*}{ S1 } & 7.26 & 2.36 & 0.40 & 3.04 & 7.38 & 2.41 & 0.40 & 2.95 \\
\cline { 2 - 9 } & \pm 0.39 & \pm 0.13 & \pm 0.04 & \pm 0.23 & \pm 0.67 & \pm 0.13 & \pm 0.01 & \pm 0.23 \\
\hline \multirow{2}{*}{ S2 } & 17.51 & 2.65 & 0.21 & 3.06 & 4.31 & 2.02 & 0.33 & 2.24 \\
\cline { 2 - 9 } & \pm 8.22 & \pm 0.65 & \pm 0.02 & \pm 0.38 & \pm 1.09 & \pm 0.12 & \pm 0.04 & \pm 0.18 \\
\hline
\end{tabular}

Table 6. Able-bodied subjects' kinematics are shown. The evolution of Movement Time (MT), Peak Velocity (PV), Total Displacement (TD) and movement smoothness (MS) are shown across two evaluation sessions. S1 was more stable that S2

\subsubsection{Case Study 2: Model Evaluation on ADLER}

The results from the case study are presented in Figures 9 and 10. The area between curves was significantly reduced for all the drink events. The new model provides a more accurate prediction of the desired functional trajectory than the old paradigm of the minimum jerk 
model. These results show that this trajectory generation scheme provides more appropriate wrist center paths for implementing functional tasks in the ADLER environment. This improvement was noted by the subject as well.

XY Plane Data Drink Task

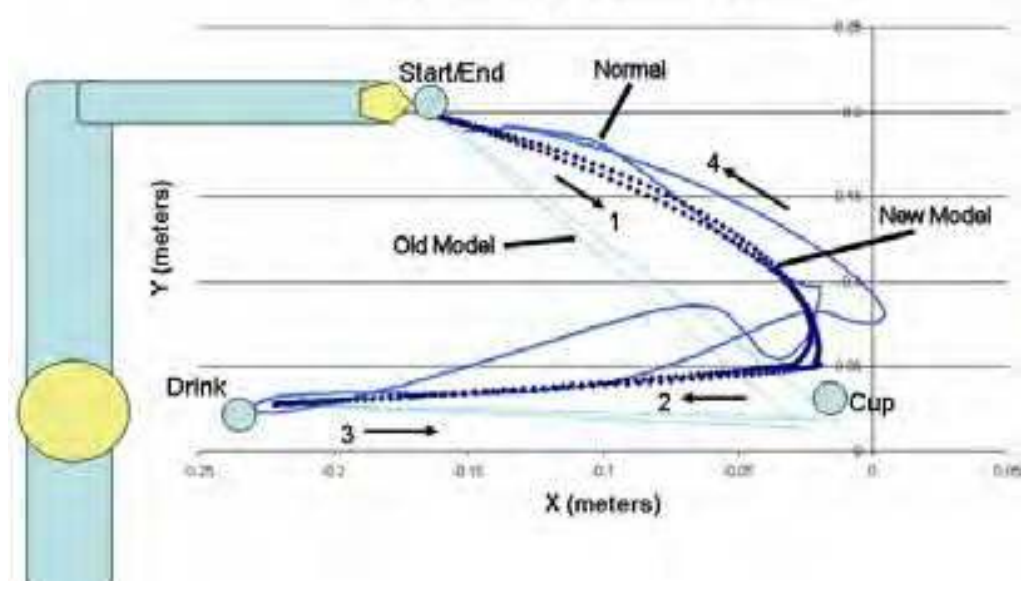

Fig. 9. XY plane data of (from top to bottom) the drink task on ADLER.

The data collected in normal mode is represented by a thick solid line, the data collected when using the old model is represented by a thin solid line (cyan), and the data collected when using the new model is represented by a dotted line. MT $=8.97 \pm 4.03$ seconds, TD $=2.23 \pm 0.33, \mathrm{PV}=0.29 \pm 4.03$, and MS $3.70 \pm 0.73$.

\section{XZ Plane Drink Task}

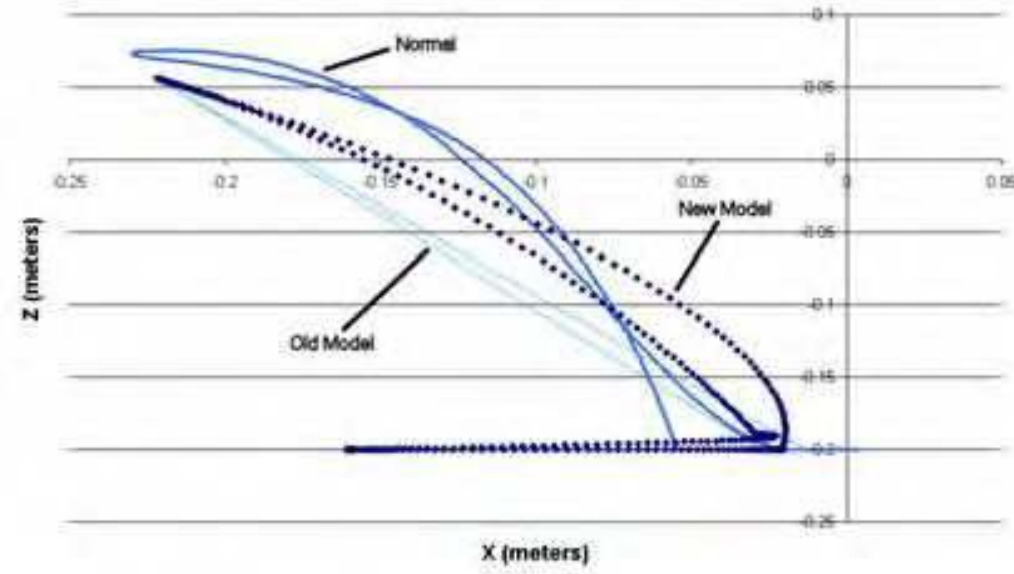

Fig. 10. XZ plane data of (from top to bottom) the drink task on ADLER.

The data collected in normal mode is represented by a thick solid line, the data collected when using the old model is represented by a thin solid line (cyan), and the data collected when using the new model is represented by a dotted line. 
Table 7 shows the average responses to the questions presented to the subject after each trial. When using the new model and asked if the robot was moving the way he would have liked to move he answered with an average value of 7 . This is a more positive response than for the old model, with which he answered 3. When using the new model and asked if he felt as though he had to work against the robot to complete the task he answered with an average value of 2 . This is a more positive response than for the old model, with which he answered 5. His comments reveal that the old model did produce movements that did not feel natural.

\begin{tabular}{|l|l|l|}
\hline \multicolumn{1}{|c|}{ Question } & \multicolumn{1}{c|}{ Response Range (1-10) } & \multicolumn{1}{c|}{ Average Response } \\
\hline $\begin{array}{l}\text { Do you feel as though the } \\
\text { robot is moving the way you } \\
\text { would like to move? }\end{array}$ & $\begin{array}{l}10=\text { Yes, completely; } 5= \\
\text { About half the time; } 1=\text { No, } \\
\text { not at all }\end{array}$ & $\begin{array}{l}\text { Model A: } 3+/-1 \\
\text { Model C: 7 +/-1 * }\end{array}$ \\
\hline $\begin{array}{l}\text { Do you feel as though you } \\
\text { need to fight against the } \\
\text { robot to complete the task? }\end{array}$ & $\begin{array}{l}10=\text { Yes, all the time; } 5= \\
\text { About half the time; } 1=\text { No, } \\
\text { not at all }\end{array}$ & $\begin{array}{l}\text { Model: } 5+/-1 \\
\text { Model: } 2+/-.5 *\end{array}$ \\
\hline
\end{tabular}

Table 7. Subject survey at the end of each trial.

The questions, possible responses, and average responses are listed. Representative comments were chosen for each model. If a result was statistically more successful by means of a t-Test it is marked with an asterisk and in bold.

The results from the questionnaire show that the differences seen between the new and old model can be felt by the subject and that using the new model provides for a more comfortable experience and more natural feeling movements. The obvious next step is to complete this analysis with stroke survivors to determine their response to the changes. Since stroke survivors are more likely to have decreased proprioception that affects their ability to sense their arm in space, we anticipate less sensitivity to changes in arm position in space. The question of whether training using these more accurate and natural movement paths will translate into the ability to dynamically position and orientate the impaired arm for various ADL artifacts (e.g., spoon, comb etc.) and the ability to use any performance improvements seen in less supervised environments.

\subsubsection{Case Study 3: Training Evaluation on ADLER}

Training improved the subject's ability to perform more functional reaching. The result of the 4 main evaluation sessions using the drink 3-D PTP patterns are illustrated in Fig. 11 and the biomechanical measures for kinematics and the clinical measures of ADL and motor function are shown in Table 8. The subject's UE-FT improved by two levels, while UE-FM scores did not change during training. However, this subject was low functioning and did not practice grasping objects, so improvement in UE-FM testing was not expected. A clinical evaluation 1 month (at about 6 weeks) after the end of training showed that the subject maintained a UE-FT score of level 4 and a UE-FM score of $24 / 66$.

Table 8 summarizes the evolution of the key kinematic variables derived for S4. We expected that the kinematic variables of movement time and smoothness (Peak V/mean V) would consistently decrease as evaluation proceeded from pre to post to follow-up and approach normal values (Rohrer et al 2002; Krebs et al. 2002; Wu et al 2000). In general this expectation was met and can be seen from the data for S1 and S2 in Tables 7and S4 in Table 8. 
We expected that the peak velocity and total displacement would consistently increase as evaluation proceeded from pre to post to follow-up and approach normal values. Table 8 clearly shows the gain in peak velocity over time. Overall total displacement was not consistent from pre- to post-training and follow-up because this measure as calculated evaluated the entire movement included those that were not useful to accomplish the task.

From Figure 11, it is clear that the subject's height off the table increased and the range of motion on the table also increased. This implies that although overall TD did not behave consistently, therefore, in the future, a better and more sensitive kinematic measure could be derived in terms of increases in height $(\mathrm{z})$ and table top range of motion ( $x-y$ area). We anticipate that when we include the FES grasp glove, especially for low-functioning stroke survivors, we will add the inclusion of a curvature and orientation measure to detect changes in dynamic orientation of the hand during functional reaching to an ADL artifact such as the cup in the drink task.

The subject used the normal mode to complete the evaluation tasks and the training modes to complete the training tasks. The drink task is shown.
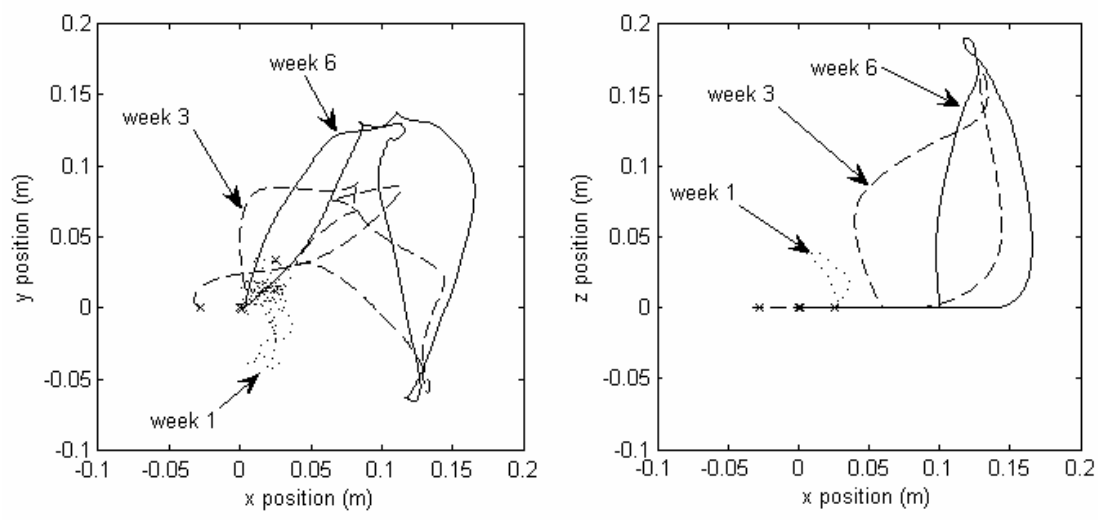

Fig. 11. Drinking Task Changes in XY and XZ planes.

The evolution of movement for the drink task are shown for the evaluation sessions from pre-training (Week 1) to follow-up (Week 6) for the drink task. The subject had increasingly more height in the $\mathrm{Z}$ direction as time passed and covered more table area in the $\mathrm{X}-\mathrm{Z}$ area.

The key changes seen translated mainly into increased shoulder and elbow movement, which lead to change from level 2 to 4 on ADL function. This result is typical of systems that training only reaching performance (Loureiro et al. 2003; Krebs et al. 2002; Prange et al. 2006). Since grasp function did not improve and is required for ADL function on levels 5 through 7 , we anticipate that training to assist opening and closing of the hand for grasping as well as reaching via the full integration of the FES game glove into the ADLER system will improve these results. In addition to gaining data from lower functioning stroke subjects, we are also evaluating the performance of higher-functioning stroke survivors with low to medium grasping capability on the ADLER system (with and without FES glove). We hope to see improvement in the UE-FM and UE-FT scores of these subjects due to more functional training. We also anticipate greater improvement following the full implementation of curved trajectory models (Model C especially). The first stroke subject was trained using PTP trajectories defined by the straight-line, 5th order minimum jerk 
model. We expect that the curved trajectories, which approximate better actual movements, will result in improved recovery.

\begin{tabular}{|c|c|c|c|c|c|c|}
\hline \multirow{2}{*}{$\begin{array}{l}\text { Evaluation } \\
\text { Session }\end{array}$} & \multicolumn{6}{|c|}{ Biomechanical and Clinical Measures } \\
\hline & MT (s) & TD (m) & PV (m/s) & MS & UE-FM & UE-FT \\
\hline \multirow[t]{2}{*}{ Initial } & 15.78 & 2.51 & 0.26 & 3.90 & \multirow{2}{*}{23} & \multirow{2}{*}{ Level 2} \\
\hline & \pm 5.65 & \pm 0.46 & \pm 0.01 & \pm 0.68 & & \\
\hline \multirow[t]{2}{*}{ Week 1} & 12.75 & 2.05 & 0.23 & 4.32 & \multirow{2}{*}{27} & \multirow{2}{*}{ Level 2} \\
\hline & \pm 4.01 & \pm 0.23 & \pm 0.10 & \pm 1.32 & & \\
\hline \multirow[t]{2}{*}{ Week 3} & 8.14 & 1.88 & 0.28 & 2.93 & \multirow{2}{*}{23} & \multirow{2}{*}{ Level 2} \\
\hline & \pm 1.42 & \pm 0.37 & \pm 0.031 & \pm 0.20 & & \\
\hline \multirow[t]{2}{*}{ Week 6} & 6.38 & 2.08 & 0.27 & 2.97 & \multirow{2}{*}{23} & \multirow{2}{*}{ Level 4} \\
\hline & \pm 0.13 & \pm 0.13 & \pm 0.03 & \pm 0.54 & & \\
\hline \multirow[t]{2}{*}{ Follow-up } & 12.59 & 2.89 & 0.36 & 3.27 & \multirow{2}{*}{24} & \multirow{2}{*}{ Level 4} \\
\hline & \pm 1.01 & \pm 0.59 & \pm 0.05 & \pm 0.94 & & \\
\hline
\end{tabular}

Table 8. Evolution of the Kinematics of S3 (Stroke) on PTP drink task.

The table shows the changes in movement time (MT), total displacement (TD), smoothness (PV/MeanV), and clinical values for motor impairment (UE-FM with 66 as maximum) and ADL function (UE-FT: Level 7 maximum).

\section{Conclusion}

This chapter discussed the development of a task-oriented therapy robot focused on real ADL training and performance. The development of the software, HERALD, and the hardware platform and FES grasp glove has been discussed. We also presented training and trajectory planning models that have been implemented with the system along with defining the pros and cons of three possible models that can be used to accurately reflect natural movement of the wrist during ADL task. We presented three case studies that briefly examined how the system has repeatable performance and has the ability to train stroke survivors. A low functioning stroke survivor was successfully trained on the system using PTP ADL-like movement. The subject's kinematics, especially movement time and movement smoothness decreased reflecting motor impairment reduction and increased motor control. The ADL functioning was improved on tasks involving more shoulder and elbow function but not on task involving grasp. In the future, the FES glove will be fully integrated in the ADLER system to allow stroke clients on all levels of motor function and ADL ability to be trained in both reaching and grasping ADLs. As such we anticipate that a major impact will then be seen on both motor impairment and functional scales.

We also presented via case study 2 different trajectory models for planning and assisting movement of the wrist using ADLER. We demonstrated that models that included curvature and had customized inputs can improve a subject's movement kinematics for an ADL tasks such as drinking and can affect their perception of the ease or difficulty of the movement. In the case study performed on the ADLER system, the subject reported a "more natural" feel when operating with the new model rather than the old model. This shows that the model appears to meet the goal of providing a more natural prediction of functional 
wrist paths. Although these results are promising it is understood that much more work to be done and there is a need to examine movements from the perspective of the stroke survivor.

In the near future, we will be improving our models for trajectory planning of ADL movements as well as examining whether the ADLER system including the FES glove can improve both motor and ADL function.

\section{References}

(AHA) American Heart Association. Heart Disease and Stroke Statistics - 2005 Update. Dallas, TX: American Heart Association; 2005

Ada L., Canning C.G., Carr J.H., Kilbreath S.L., Shepherd R.B. “Task-specific training of reaching and manipulation." In Insights into Reach to Grasp movement. K.M.B. Bennett and U. Castiello (Editors). Elsevier Science B.V. 1994

Abend W, Bizzi E, Morasso P: Human arm trajectory formation. Brain 1982, Vol 105, pp. 331-348.

Amirabdollahian, F, (2003). An investigation of roboti-mediated therapies and therapy effects on the recovery of upper limb post stroke. University of Reading, Department of Cybernetics, Dissertation Thesis. September.

Amirabdollahian, F.; Loureiro, R. \& Harwin, W., (2002). Minimum jerk trajectory control for rehabilitation and haptic applications. Proceedings of IEEE Int Conf on Robotics Automation, Washington DC, May, pp. 3380-3385.

Atkeson CG, Hollerbach JM: Kinematic features of unrestrained vertical arm movements. Journal of Neuroscience 1985, 5(9): 2318-2330.

Aycock DM. Blanton S. Clark PC. Wolf SL. What is constraint-induced therapy? Rehabilitation Nursing. 29(4):114-5, 121, 2004

Bach y Rita P, Wood S, Leder R, Paredes O, Bahr D, Bach-y-Rita EW, Murillo N. “Computer assisted motivating rehabilitation for institutional, home, and educational late stroke programs." Top Stroke Rehabil, Vol. 8, Issue 4, pp. 1-10, 2002

Barton, L. A. \& Wolf, S. L., (1993). Learned nonuse in the hemiplegic upper extremity. In Gordon WA, Editor. Advances in Stroke Rehabilitation. Boston: ButterworthHeinemann; pp. 79-87, 1993

Bayona, NA.;Bitensky, J.; Salter, K. \& Teasell, R. (2005a). The role of task-specific training in rehabilitation therapies. Topics in Stroke Rehabilitation, Vol. 12, Issue 3, pp. 58-65, 2005a

Burgar, C.G.; Lum, P.S.; Shor, P.C. \& Van der Loos, H.F.M., (2000) Development of robots for rehabilitation therapy:the Palo Alto VA/Stanford experience, Journal of Rehabilitation RED, Vol. 36, Issue 6, November/December.

Carr J, Shepherd R. A Motor Relearning Programme For Stroke. 2nd edn. Heinemann Medical, Oxford; 1987

Calautti, C. \& Baron, J., (2003). Functional neuroimaging studies of motor recovery after stroke in adults. A review. Stroke, Vol. 34, pp. 1553-66.

Fasoli, S.; Krebs, H.I.; Stein, J.; Frontera, W.R. \& Hogan, N., (2003). Effects of robotic therapy on motor impairment and recovery in chronic stroke. Archives of Phys Med Rehabil, vol. 84, pp. 477-84.

Fasoli, S.;Krebs, H. I.; Hughes, R., Stein J. \& Hogan N., (2005). Functionally-based rehabilitation: Benefits or Buzzwrod? Proceedings of International Conference on Rehabilitation Robotics ICORR), Chicago, IL, June 28-July 1, pp. 223-226, 2005. 
FCS Control Systems HapticAPI Programming Manual, Version 1.2, Schipol, The Netherlands: FCS Control Systems, 2003.

Fisher, B. E. and Sullivan, K. J., “Activity-Dependent factors affecting poststroke functional outcomes." Top Stroke Rehabil, Vol. 8, Issue 3, pp. 31-44, 2001

Flash, T. \& Hogan, N., (1985). The coordination of arm movements: An experimentally confirmed mathematical model. The Journal of Neuroscience, Vol. 5, pp. 1688-1703.

Fugl-Meyer, A.R.; Jaasko L. \& Leyman I:, (1975). The post-stroke hemiplegic patient. A method for evaluation of physical performance. Scandinavian Journal of Rehabilitation Medicine, Vol. 7, pp. 13-31.

Gentilucci, M.; Castiello, U.; Corradini ML., Scarpa M., Umilta C., \& Rizzolatti G., (1991). Influence of different types of grasping on the transport component of prehension movements. Neuropsychologia. Vol. 29, Issue 5, 361-78.

Gentilucci, M., (2002). Object motor representation and reaching-grasping control." Neuropsychologia. Vol. 40, Issue 8, pp. 1139-53.

Gentilucci, M.; Daprati, E.; Gangitano, M.;Saetti, M.C. \& Toni, I., (1996). On orientating the hand to reach and grasp an object. Neuroreport. Vol. 7, pp. 589-592.

Hogan, N. \& Flash, T (1987). Moving gracefully: quantitative theories of motor coordination. TINS. Vol. 10, Issue 4, pp. 170-174.

Hogan, N. (1984) An organizing principle for a class of voluntary movements," Journal of Neuroscience, Vol. 4, pp. 2745-2754

He Huang, H., Wolf, S.L. \& He J. (2006) Recent developments in biofeedback for neuromotor rehabilitation. Journal of NeuroEngineering and Rehabilitation. Vol. 3, Issue 11. doi:10.1186/1743-0003-3-11

He, J.; Koeneman, E.J.; Schultz, R.S.; Huang, H.; Wanberg, J.; Herring, D.E.; Sugar, T.; Herman, R.; \& Koeneman, J.B., (2005). Design of a robotic upper extremity repetitive therapy device. 9th International Conference on Rehabilitation Robotics, 2005. (ICORR 2005) Volume, Issue , 28 June-1 July 2005, pp. 95 - 98

Hunter, P.; Peckham, P. \& Knutson, J.S., (2005). Functional electrical stimulation for neuromuscular applications. Annu. Rev. Biomed. Eng. Vol 7: pp. 327-60,

Johnson, M.J.; Wisneski, K.J.; Anderson. J.; Nathan, D., \& Smith. R., (2006) Development of ADLER: The Activities of Daily Living Exercise Robot. IEEE-EMBS Biomedical Robotics (BioRob 2006), February 2006, Pisa, Italy, pp. 881-886.

Kahn, L. E., Zygman, M. L., Rymer, W. Z. \& Reinkensmeyer, D.J., (2006). Robot-assisted reaching exercise promotes arm movement recovery in chronic hemiparetic stroke: a randomized controlled pilot study. Journal of NeuroEngineering and Rehabilitation 2006, Vol. 3, Issue 12, doi:10.1186/1743-0003-3-12

Krebs, H.I.; Palazzolo, J.J.; Dipietro, L.; Ferraro, M.; Krol, J.; Rannekleiv, K.; Volpe, B.T. \& Hogan, N., (2003). Rehabilitation robotics: Performance-based progressive robotassisted therapy. Autonomous Robots, Vol. 15, pp. 7-20.

H.I. Krebs, B.T. Volpe, et al., "Robot-aided neurorehabilitation: from evidence-based to science-based rehabilitation," Top Stroke Rehabil, vol. 8, no. 4, pp. 54-70, 2002.

Latash, M. L. \& Nicholas, J.J. (1996). Motor control research in rehabilitation medicine. Disability E Rehabilitation. Vol. 18, Issue 6, pp. 293-9.

Liepert, H.; Bauder, W., Miltner, H.R. ; Taub, E. \& Weiller, C., (2002). Treatment-induced cortical reorganization after stroke in humans. Stroke, Vol. 31, pp. 1210-1216.

Loureiro, R.; Amirabdollahian, F.; Topping, M.; Driessen, B. \& Harwin, W., (2003). Upper limb robot mediated stroke therapy-GENTLE/s approach. Autonomous Robots Vol. 15, Issue 1, pp. 35-51. 
Ma, H. \& Trombly, C. A. (2002). A synthesis of the effects of occupational therapy for persons with stroke, Part II: Restoration of roles, tasks, and activities. Am J Occup Ther, Vol. 56, No. 3, pp. 260-74

Maclean N, Pound P, Wolfe C, Rudd A: Qualitative analysis of stroke patients motivation for rehabilitation. British Medical Journal 2000, 321(7268):1051-1054.

MacClellan, L.R.; Bradham, D.D.; Whitall, J.; Volpe, B.; Wilson, P.; Ohlhoff, J.; Meister, C.; Hogan,N.; Krebs, H.I. \& Bever Jr, C., (2006) Robotic upper-limb neurorehabilitation in chronic stroke patients. Journal of Rehabilitation RED, Vol. 42, No. 6, November/December, pp. 717-722

Merians, A.S.; Jack, D.; Boian, R.; Tremaine, M.; Burdea,G.C.; Adamovich,S.V.; Recce, M. \& Poizner H., (2002).Virtual Reality-Augmented Rehabilitation for Patients Following Stroke. Physical Therapy. Vol. 82, No. 9 . September 2002, pp. 898-915

Michaelsen, S.M.; Jacobs, S.; Roby-Brami, A. \& Levin, M.F. (2004) Compensation for distal impairments of grasping in adults with hemiparesis." Experimental Brain Research, Vol. 157, Issue 2, pp. 162-73.

Nathan and Johnson - ICORR 2007

Nelles, G., W. Jentzen, et al. (2001) Arm training induced brain plasticity in stroke studied with serial positron emission tomography. Neuroimage, Vol. 13, Issue 6 Pt 1, pp. 1146-54

Nef T, Mihelj M, Colombo G, Riener R. “ARMin - Robot for Rehabilitation of the Upper Extremities." IEEE International Conference on Robotics and Automation, pp. 31523157, Orlando, Florida, May 15-19, 2006

Page, S.J.; Sisto, S.; Levine, P.; \& McGrath, R.E., (2004). Efficacy of modified constraintinduced movement therapy in chronic stroke: a single-blinded randomized controlled trial. Arch Phys Med Rehabil, Vol. 85, pp. 14-8.

Patton, J.L.; Kovic, M. \& Mussa-Ivaldi, F.A. (2006). Custom-designed haptic training for restoring reaching ability to individuals with stroke. Journal of Rehabilitation Research and Development, In press, 2006.

Patton, J.L.; Stoykov, M.E.; Kovic, M. \& Mussa-Ivaldi, F.A., (2006). Evaluation of robotic tr aining forces that either enhance or reduce er $\mathrm{r}$ or in chronic hemipar etic stroke survivor s. Exp Brain Res, Vol. 168, pp. 368-383.

Patton, J.L. \& Mussa-Ivaldi, F.A. (2004) Robot-assisted adaptive training: custom force fields for teaching movement patterns. IEEE Transactions on Biomedical Engineering. Vol. 51, Issue 4, pp. 636-46.

Prange, G. B.; Jannink M. J. A; Groothuis-Oudshoorn, C. G. M.; Hermens, H. J. \& IJzerman, M. J., (2006). Systematic review of the effect of robot-aided therapy on recovery of the hemiparetic arm after stroke. Journal of Rehabilitation RED, Vol. 43, No. 2, March/April, pp. 171-184

Reinkensmeyer, D.J.; Takahashi, C.D.; Timoszyk, W.K.; Reinkensmeyer, A. N. \& Kahn, L.E., (2001). Design of robot assistance for arm movement therapy following stroke. Advanced Robotics, Vol. 14, No. 7, pp. 625-637.

Roby-Brami, A.; Jacobs, S.; Bennis, N. \& Levin, M.F., (2003) Hand orientation for grasping and arm joint rotation patterns in healthy subjects and hemiparetic stroke patients." Brain Research, Vol. 969, issues 1-2, pp. 217-29.

Rohrer, B.; Fasoli, S.; Krebs, H.I.; Hughes, R.; Volpe, B.; Frontera, W.R.; Stein, J. \& Hogan, N., (2002). Movement smoothness changes during stroke recovery. Journal of Neuroscience, Vol. 22, Issue 18, pp. 8297-304. 
Schaechter, J.D., (2004) .Motor rehabilitation and brain plasticity after hemiparetic stroke. Progress in Neurobiology. Vol. 73, Issue 1, pp. 61-72.

Simone, L.K. \& Kamper, D.G., (2005) . Design considerations for a wearable monitor to measure finger posture. Journal of NeuroEngineering and Rehabilitation, Vol 2, Issue 5 , doi:10.1186/1743-0003-2-5

Sterr, A.; Freivogel, S. \& Schmalohr, D. (2000). Neurobehavioral aspects of recovery: Assessment of the learned nonuse phenomenon in hemiparetic adolescents. Arch Phys Med Rehabil. Vol. 83, No. 4, pp. 1726-31

Thielman G.T., Dean C.M., Gentile A.M. “Rehabilitation of reaching after stroke: task related training versus progressive resistive exercise.," Arch Phys Med Rehabil, Vol. 85, pp. 1613-1618. 2004

Trombly, C. A. \& Ma, H. (2002). A synthesis of the effects of occupational therapy for persons with stroke, Part I: Restoration of roles, tasks, and activities. Am J Occup Ther, Vol. 56, No. 3, pp. 250-59.

Trombly C. Occupational Therapy of Physical Dysfunction. Trombly C, editor. Baltimore (MD): Williams \& Wilkins; 1995

Taub E, Uswatte G, Pidikiti R. Constraint-induced movement therapy: a new family of techniques with broad application to physical rehabilitation -- a clinical review. J Rehabil Res Dev. 36(3): 1-18, 1999

Taub, E.; Crago, J.E.; Burgio LD, et al., (1994). An operant approach to rehabilitation rehabilitation medicine: overcoming learned nonuse by shaping. Journal of Experiment Analysis of Behavior. Vol. 61, pp. 281-93.

Taub, E.; Lum, P. S.; Hardin, P.; Mark V. \& Uswatte. G., (2005). AutoCITE, Automated delivery of CI therapy with reduced effort by therapists. Stroke, Vol. 36, pp. 1301.

Tyberghein J., E. Sunshine, (2004, Aug 13). "Crystal Space 0.98 manual," available: http://www.crystalspace3d.org/docs/online/manual-0.98/.

Wilson DJ, Baker LL, Craddock JA: Functional test for the hemipar etic upper extremity. Am J Occup Ther 1984, 38(3):159-164.

Wisneski, K.J. \& Johnson, M.J. (2006) Insights into Modeling Functional Trajectories for Robot-Mediated Daily Living Exercise Environments." IEEE-RAS Biomedical Robotics (BioRob 2006), February 2006.

Wisneski K. Development of a Model for Functional Upper Extremity Trajectory Generation and Implementation on the Activities of Daily Living Exercise Robot (ADLER). Masters Thesis, Marquette University, Department of Biomedical Engineering, August 2006.

Wisneski, K.J. \& Johnson, M.J. (2007). Quantifying kinematics of purposeful movements to real, imagined, or absent functional objects: Implications for modelling trajectories for robot-assisted ADL tasks. Journal of NeuroEngineering and Rehabilitation, Vol 4, Issue 7, doi:10.1186/1743-0003-4-7

Woldag, H.; Waldmann, G.; Heuschkel, G. \& Hummelsheim, H., (2003). Is the repetitive training of complex hand and arm movements beneficial for motor recovery in stroke patients?. Clinical Rehabilitation. Vol. 17, Issue 7, pp. 723-30.

Wood, S. R., N. Murillo, et al., (2003). Motivating, game-based stroke rehabilitation: a brief report. Top Stroke Rehabil, Vol. 10, Issue 2, pp. 134-40.

Wu C., Trombly C.A,. Lin K, \& Ticke-Degnen L. (1998). Effects of object affordances on reaching performance in persons with and without cerebrovascular accident. Am J Occup Ther 1998 
Wu C., Trombly C.A., Lin K, et al., (2000). A kinematic study of contextual effects on reaching performance in persons with and without stroke: Influences of object availability. Arch Phys Med Rehabil, Vol. 81, Issue 1, pp. 95-101.

Volpe BT, Ferraro M, Lynch D, Christos P, Krol J, Trudell C, Krebs HI, Hogan N., (2002). Robotics and other devices in the treatment of patients recovering from stroke. Current Neurology E Neuroscience Reports, Vol. 5, Issue 6, pp. 465-70. 




\author{
Rehabilitation Robotics \\ Edited by Sashi S Kommu
}

ISBN 978-3-902613-04-2

Hard cover, 648 pages

Publisher I-Tech Education and Publishing

Published online 01, August, 2007

Published in print edition August, 2007

The coupling of several areas of the medical field with recent advances in robotic systems has seen a paradigm shift in our approach to selected sectors of medical care, especially over the last decade.

Rehabilitation medicine is one such area. The development of advanced robotic systems has ushered with it an exponential number of trials and experiments aimed at optimising restoration of quality of life to those who are physically debilitated. Despite these developments, there remains a paucity in the presentation of these advances in the form of a comprehensive tool. This book was written to present the most recent advances in rehabilitation robotics known to date from the perspective of some of the leading experts in the field and presents an interesting array of developments put into 33 comprehensive chapters. The chapters are presented in a way that the reader will get a seamless impression of the current concepts of optimal modes of both experimental and ap- plicable roles of robotic devices.

\title{
How to reference
}

In order to correctly reference this scholarly work, feel free to copy and paste the following:

Michelle J. Johnson, Kimberly J. Wisneski, John Anderson, Dominic Nathan, Elaine Strachota, Judith Kosasih, Jayne Johnston and and Roger O. Smith (2007). Task-oriented and Purposeful Robot-Assisted Therapy, Rehabilitation Robotics, Sashi S Kommu (Ed.), ISBN: 978-3-902613-04-2, InTech, Available from: http://www.intechopen.com/books/rehabilitation_robotics/task-oriented_and_purposeful_robotassisted_therapy

\section{INTECH}

open science | open minds

\author{
InTech Europe \\ University Campus STeP Ri \\ Slavka Krautzeka 83/A \\ 51000 Rijeka, Croatia \\ Phone: +385 (51) 770447 \\ Fax: +385 (51) 686166 \\ www.intechopen.com
}

\author{
InTech China \\ Unit 405, Office Block, Hotel Equatorial Shanghai \\ No.65, Yan An Road (West), Shanghai, 200040, China \\ 中国上海市延安西路65号上海国际贵都大饭店办公楼 405 单元 \\ Phone: +86-21-62489820 \\ Fax: +86-21-62489821
}


(C) 2007 The Author(s). Licensee IntechOpen. This chapter is distributed under the terms of the Creative Commons Attribution-NonCommercial-ShareAlike-3.0 License, which permits use, distribution and reproduction for non-commercial purposes, provided the original is properly cited and derivative works building on this content are distributed under the same license. 